of infection could not be confirmed, although three patients had taken $A B$ before sampling. It is important for physicians to have a suspicion for non-infectious arthritis, especially in patients with clinical and blood test result dissociation, radiological $\mathrm{CC}$, medical history of hyperuricemia or psoriasis, in order to avoid unnecessary $A B$ and surgical treatment.

References:

[1] Merit P. George, Floranne C. Ernste, Aaron Tande, Douglas Osmon, Tad Mabry, Elie F. Berbari. Clinical Presentation, Management, and Prognosis of Pseudogout in Joint Arthroplasty: A Retrospective Cohort Study. J. Bone Joint Infect. 2019, Vol. 4 (1): 20-26

Disclosure of Interests: None declared

DOI: 10.1136/annrheumdis-2020-eular.2118

\section{AB1323-HPR A QUALITATIVE EXPLORATION OF THE PERSONAL FINANCIAL TOLL OF ARTHRITIS}

D. Berkovic ${ }^{1}$, D. Ayton ${ }^{1}$, A. M. Briggs ${ }^{2}$, I. Ackerman ${ }^{1} .{ }^{1}$ Monash University, Melbourne, Australia; ${ }^{2}$ Curtin University, Melbourne, Australia

Background: The financial experience faced by working-age people with arthritis includes living below the poverty line for many (1). Financial distress amongst people with arthritis is known to contribute to poorer health outcomes, including high psychological distress and more severe pain (2). Despite the demonstrated societal cost of arthritis care and management, the personal costs borne by the individual are not well understood in different health systems (3).

Objectives: To explore the perceived financial impacts of living with arthritis amongst working-age individuals aged $18-50$ years in Australia.

Methods: A qualitative descriptive study design was used. Participants with inflammatory arthritis or osteoarthritis were recruited from the community, including urban and rural settings. An interview schedule was developed, informed by existing literature (4), which was piloted prior to data collection. Deductive and inductive coding techniques were used to identify financial-related themes arising from the data.

Results: Semi-structured interviews were conducted with 21 younger people ( $90 \%$ female) with a mix of arthritis conditions including rheumatoid arthritis, psoriatic arthritis, osteoarthritis, and ankylosing spondylitis. Four themes were identified: direct arthritis-attributable medical costs, indirect arthritis-attributable costs, insurance and pension costs, and broader financial impacts on the family. Non-subsidised costs were frequently referenced by participants as burdensome, and existed even within the publically-funded healthcare system. Financial distress was characterised by participants as chronic, onerous for the entire family, and associated with exacerbation of physical symptoms.

Conclusion: People with arthritis and of working age experience significant arthritis-attributable financial burden and related distress. Financial concerns should be actively identified and considered within shared clinical decision making, in order to provide more patient-centred care for these individuals.

References:

[1] Rios R, Zautra AJ. (2011). Socioeconomic Disparities in Pain: The Role of Economic Hardship and Daily Financial Worry. Health Psychol. 30(1) 58-66.

[2] Yilmaz V, Umay E, Gundogdu I, Kaaahmet ZO, Ozturk AE. (2017). Rheumatoid Arthritis: Are psychological factors effective in disease flare? Eur $\mathrm{J}$ Rheumatol. 4(2) 127-132

[3] Schofield D, Rupendra S, Cunich C. Counting the Cost Part 2: Economic Costs: The current and future burden of arthritis. The University of Sydney: Arthritis Australia; 2016.

[4] Ackerman IN, Kemp JL, Crossley KM, Culvenor AG, Hinman RS. (2017). Hip and Knee Osteoarthritis Affects Younger People, Too. J Orthop Sports Phys Ther. 47(2) 67-79.

Disclosure of Interests: None declared

DOI: 10.1136/annrheumdis-2020-eular.1460

\section{AB1324-HPR INVESTIGATION OF THE RELATIONSHIP BETWEEN SOCIAL APPEARANCE ANXIETY AND DISEASE DURATION, SELF-ESTEEM, ANXIETY AND DEPRESSION IN RHEUMATOLOGICAL DISEASES- PRELIMINARY STUDY}

S. Y. Cetin ${ }^{1}$, A. Ayan ${ }^{2}$, A. Buyuk ${ }^{3}$, T. Can Akman ${ }^{4} .{ }^{1}$ Akdeniz University, Department of Physiotherapy and Rehabilitation, Antalya, Turkey; ${ }^{2}$ Antalya Training and Research Hospital, Rheumatology, Antalya, Turkey; ${ }^{3}$ Akdeniz University, Physiotherapy and Rehabilitation, Antalya, Turkey; ${ }^{4}$ Pamukkale University, Physiotherapy and Rehabilitation, Denizli, Turkey

Background: Appearance anxiety means discomfort in social interactions due to changes in appearance. Also this anxiety; it is the fear of being evaluated negatively and worry about the changes in appearance, and it is not only apparent. Body image is the emotions, thoughts and perceptions of the individual about his or her own body and directly affects self-esteem. The Social Appearance Anxiety Scale (SAAS) was developed to assess social appearance anxiety, and this scale was found to be a valid and reliable scale in scleroderma (SSc) patients. It was also thought to be related to the severity of the disease. The literature shows that appearance concerns are strongly related to depression in patients with rheumatic disease and should be evaluated routinely.

Objectives: The first aim of the study is to determine the level of social appearance anxiety in rheumatology patients, and our last goal is to investigation of the relationship between social appearance anxiety and disease duration, self-es teem, depression and anxiety.

Methods: 129 rheumatology patients with a mean age of $42.96 \pm 11.33$ years $(51$ men, 78 women) were included in the study. $55 \%$ of patients were ankylosing spondylitis (AS), $15.5 \%$ of patients were sjögren syndrome (SS), $11.6 \%$ of patients were rheumatoid arthritis (RA), $7.8 \%$ of patients were fibromyalgia syndrome (FMS), $6.2 \%$ of patients were SSc, $2.3 \%$ of patients were Behçet's disease (BD) and $1.6 \%$ were diagnosed with psoriatic arthritis (PsA). The Social Appearance Anxiety Scale (SAAS) was used to evaluate patients' social appearance anxiety, the Rosenberg Self-Esteem Scale (RSES) was used to evaluate self-esteem, and the Hospital Anxiety and Depression Scale (HADS) was used to evaluate depression and anxiety. Results: The disease duration was found to be $6.82 \pm 5.22$ years. The SAAS average was found to be $43.23 \pm 20.53$ points. It was found that the SAAS values of patients with PsA and SSc were higher than patients with AS, RA, FMS SS, BD. A moderate positive correlation was found between SAAS and disease duration, depression and anxiety ( $p: 0.048, r: 0.545 ; p: 0.007, r: 0.638 ; p: 0.014$ r: 0.749 , respectively)

Conclusion: As a result of the study, it was observed that rheumatology patients had moderate and high level social appearance anxiety. We thought that they have a higher level of social appearance anxiety because of skin involvement in patients with with PsA and SSc. In addition, as a result of the study, we found that as the social appearance anxiety increased, disease duration, depression and anxiety increased. According to this study, in which the preliminary results are given, we thought that it is necessary to determine patients' appearance anxiety in routine evaluation and to reduce social appearance anxiety by collaboration with multidisciplinary areas in rheumatological diseases.

References:

[1] Mills SD, Kwakkenbos L, Carrier ME, Gholizadeh S, Fox RS, Jewett LR, Gottesman K, Roesch SC, Thombs BD, Malcarne VL. Scleroderma Patient-centered Intervention Network InvestigatorsValidation of the Social Appearance Anxiety Scale in Patients With Systemic Sclerosis: A Scleroderma Patient-Centered Intervention Network Cohort Study Arthritis Care Res (Hoboken) 2018; 70 (10): 1557-1562.

[2] Jung J, Lee S-H. Behavior between korean and U.S. women cross-cultural comparisons of appearance selfschema, body image, self-esteem, and dieting. Family and Consumer Sciences Research Journal 2006; 34: 350.

[3] Hart TA, Flora DB, Palyo SA, Fresco DM, Holle C, Heimberg RG. Development and examination of the Social Appearance Anxiety Scale. Assessment 2008;15:48-59.

[4] Monaghan SM, Sharpe L, Denton F, Levy J, Schrieber L, Sensky T. Relationship Between Appearance and Psychological Distress in Rheumatic Diseases Arthritis Rheum 2007; 57 (2): 303-9

Disclosure of Interests: None declared

DOI: 10.1136/annrheumdis-2020-eular.5235

\section{AB1325-HPR $\quad$ THE TRANSITION FROM PEDIATRIC TO ADULT RHEUMATOLOGY OF 347 PATIENTS AT A SINGLE} CENTER

S. Ugurlu ${ }^{1}$, B. H. Egeli ${ }^{1}$, A. Adrovic ${ }^{1}$, K. Barut ${ }^{1}$, S. Sahin ${ }^{1}$, M. Yildiz ${ }^{1}$,

O. Kasapcopur ${ }^{1}$, H. Ozdogan ${ }^{1} .{ }^{1}$ Istanbul University- Cerrahpasa, Istanbul, Turkey

Background: Pediatric to adult rheumatology transition can be a challenge for both the patient and the clinician, especially in rheumatology as it includes chronic diseases with close follow-up.

Objectives: The objective of this study is to understand our tertiary rheumatology center patient demographic transitioning from pediatric to adult rheumatology in order to design prospective studies enhancing the evidence of transition recommendations.

Methods: Patients included in this study are regularly followed-up in our adult rheumatology clinic and were regularly followed up in our pediatric rheumatology clinic in the past. They were all diagnosed with a rheumatologic condition receiving treatment. The patient files were assessed to have a better understanding of their demographic, disease and treatment information.

Results: Our cohort includes 347 patients diagnosed with a variety of conditions that are Familial Mediterranean Fever (FMF) $(n=216)$, Juvenile Idiopathic Arthritis (JIA) ( $n=56)$, Juvenile Spondyloarthritis (jSPA) $(n=39)$, Systemic Lupus Erythematosus (SLE) ( $n=20)$, Behçet's Disease $(n=7)$ and the rest of the rheumatologic conditions with less than 5 patients each. The mean age of the patients during transition, mean age of diagnosis, and follow-up duration are $21.34 \pm 1.7$ $10.4 \pm 4.18$, and $10.82 \pm 4.4$ in respective order. The treatment regimens the patients received are summarized in Table 1. 
Table 1. Current Treatment Information of the Patients

\begin{tabular}{lr}
\hline Current Treatment Information & \\
\hline DMARD & 26 \\
Colchicine & 23 \\
Adalimumab & 21 \\
Etanercept & 10 \\
NSAID & 4 \\
Tocilizumab & 3 \\
Cyclophosphamide & 3 \\
Rituximab & 2 \\
Prednisolone & 7 \\
Mycophenolate Mofetil & 1 \\
Canakinumab & 1 \\
\hline
\end{tabular}

Seven patients had FMF related attacks. In addition to attacks, one FMF patient had bilateral ankle pain and one patient had leg pain. One patient out of three diagnosed with Takayasu's disease was still symptomatic. One patient had uveitis-related symptoms. One patient diagnosed with SLE had skin dryness. Furthermore, there were patients with sequelae formation. One patient diagnosed with oligoarticular JIA (OJIA) had bilateral hip sequela with the additional left hip prosthesis. One oJIA patient had micrognathia, and one had left knee sequela. One pJIA patient had small joint sequelae. One sJlA patient had bilateral hip sequelae. One jSPA patient had enthesopathy. One FMF patient had proteinuria due to amyloidosis formation. Another FMF patient had hip surgery due to sequela.

Conclusion: Our center had patients with a variety of conditions with different natures of diseases. EULAR recommends the transition process to start no later than 14 years of age; however, this process started at the mean age of 21 in our patients. In most of these patients, especially the ones diagnosed with FMF, the control of disease activity was maintained. The transition of these different clinical entities might require certain amendments to the standard of care. For future references, we will be able to understand more about the adulthood prognosis of these clinical entities.

Disclosure of Interests: None declared

DOI: 10.1136/annrheumdis-2020-eular.3436

\section{AB1326-HPR TOBACCO ADDICTION IN PEOPLE WITH RHEUMATOID ARTHRITIS - FROM THE PERSPECTIVE OF PATIENTS}

B. A. Esbensen ${ }^{1,2}$, I. K. Roelsgaard ${ }^{1}$, S. K. Larsen ${ }^{1}$, T. Thomsen ${ }^{2,3}$

${ }^{1}$ Copenhagen Center for Arthritis Research (COPECARE), Center for

Rheumatology and Spine Diseases, Glostrup, Denmark; ${ }^{2}$ University of

Copenhagen, Department of Clinical Medicine, Copenhagen, Denmark; ${ }^{3} \mathrm{Herlev}$ and Gentofte Hospital, Copenhagen, Herlev Acute, Critical and Emergency

Care Science Unit, Department of Anaesthesiology, Herlev, Denmark

Background: Smoking is one of the most significant modifiable exosomes risk factors for rheumatoid arthritis (RA) (1). Studies suggest that $25-30 \%$ of people with RA in Denmark smoke (2). This is almost twice as many as in the background population in Denmark. People with RA have a significant increased risk of severe comorbidity including cardiovascular disease. In addition, there are indications that smokers with RA have a poorer effect of the medical inflammatory treatment compared to non-smokers, and consequently more difficult to achieve remission of the disease activity (3). Tobacco addiction is complex and can be a challenge in smoking cessation. In addition to physiological dependence, habits and social and environmental factors may influence addiction. Tobacco smoking is associated with an addiction to nicotine and it is unexplored how this addiction appears in people with RA.

Objectives: The aim of this study was to examine from the patient's perspective how tobacco addiction appears in people with rheumatoid arthritis.

Methods: We conducted a qualitative study based on a hermeneutics approach. People with RA who previously had participated in a randomized controlled study (4) about smoking cessation conducted at the Center for Rheumatology and Spine Diseases at Rigshospitalet, Denmark were recruited for semi-structured interviews.

Results: In total, 12 people with RA (50\% female) were included in the study. The median age was 62 years and median RA disease duration was 12 years. The degree of physical dependence measured by Fagerströms Test for Nicotine dependence (FTND) was on average: 4.9 (score: 0-10, 0=nonphysical dependence).

Three categories of how tobacco addiction appeared emerged during the analysis: 1) It develops into ingrown habits referring to the fact that smoking already in adolescence contributes to the development of specific physical, mental and social smoking behavior. Not all individuals considered themselves addicted to nicotine as they did not necessarily connect the nicotine to the ingrown habits. 2) The body craves for nicotine referring to nicotine proved calming, while a lacking or insufficient dose caused withdrawal symptoms. Furthermore, smoking became a habit where a craving for smoking occurred in certain situations. 3)
Ambivalence - for and against referring to the physical dependence and smoking habits making a smoking cessation difficult. Dependency to nicotine and challenges to quit smoking led to a feeling of ambivalence and a lack of control. Conclusion: Tobacco addiction appeared as a physical dependence and a habit, which, during a smoking cessation, led to ambivalent feelings. Therefore, based on this study, there is still a need for health professionals to talk to patients about smoking. But also, a need to articulate the complexity of addiction in order to support for smoking cessations. Information should be strengthened in the clinical practice in relation to nicotine's implication in tobacco addiction as well as the consequences of tobacco smoking for individuals with RA.

References:

[1] Scott DL, Wolfe F, Huizinga TW. Lancet. 2010 \#\#\#

[2] Loppenthin K, Esbensen BA, Jennum P, Ostergaard M, Tolver A, Thomsen T, et al. Clin Rheumatol. 2015. \#\#\#

[3] Roelsgaard IK, Ikdahl E, Rollefstad S, Wibetoe G, Esbensen BA, Kitas GD et al. Rheumatology (Oxford). 2019. \#\#\#

[4] Roelsgaard IK, Thomsen T, Ostergaard M, Christensen R, Hetland ML, Jacobsen S, et al. Trials. 2017;18(1):570.\#\#\#

Disclosure of Interests: None declared

DOI: 10.1136/annrheumdis-2020-eular.965

\section{AB1327-HPR SELF-ASSESSMENT OF ORAL HEALTH STATUS IN RHEUMATOID ARTHRITIS, SYSTEMIC LUPUS ERYTHEMATOSUS AND CONTROLS}

C. M. Gamboa-Alonso ${ }^{1}$, J. D. Ángulo ${ }^{1}$, M. J. Garza Martínez ${ }^{1}$, G. FigueroaParra $^{1}$, A. L. De-Leon-Ibarra ${ }^{1}$, J. C. Riegatorres ${ }^{1}$, D. Á. Galarza-Delgado'. ${ }^{1}$ Hospital Universitario José Eleuterio González, Rheumatology, Monterrey, Mexico

Background: Different periodontal disorders have been associated with the development of multiple rheumatic diseases, encouraging the production of citrullinated proteins and creating a proinflammatory state with an increase in oral and systemic symptomatology.

The Geriatric/General Oral Health Assessment Index (GOHAI) survey has been used as a self-assessment tool where studies have found a diminished quality of oral health in Rheumatoid Arthritis (RA). ${ }^{1}$

Objectives: Compare the behavior of GOHAl survey in RA, Systemic lupus erythematosus (SLE), and controls in a Rheumatology center at Northeast Mexico.

Methods: We performed a descriptive study of patients with RA and LES who answered the Spanish version of GOHAI survey. A control group was also included.

GOHAI survey consists of 12 Questions with Likert answers evaluating problems related to periodontal disease in the last 3 months.

Questions 1-4 evaluate physical function, 6, 7, 9-11 psychosocial status and 5, 8 and 12 pain.

Results: Sixty RA patients, 32 SLE patients and 46 controls were included. Groups were adjusted by sex and age.

GOHAl survey presented a total mean of 23.4 in RA, 22.06 in SLE and 21.54 in controls with a maximum score of 60 points.

When analyzing the survey in physical function and psychosocial status a statistical significant difference was found when comparing RA group to controls.

Table 1. Comparison between GOHAl index scores in RA, SLE and control groups

\begin{tabular}{|c|c|c|c|c|}
\hline & RA $n=60$ & SLE $n=32$ & $\begin{array}{c}\text { Controls } \\
n=46\end{array}$ & \\
\hline & Median (SD) & Median (SD) & Median (SD) & $\begin{array}{l}\text { RA vs RA and Three } \\
\text { SLE controls groups }\end{array}$ \\
\hline Age & $51.27(15.84)$ & $37.03(14.14)$ & $41.07(11.25)$ & 0.17 \\
\hline Sex & $58(96.67 \%)$ & $29(90.62 \%)$ & $42(91.3 \%)$ & \\
\hline $\begin{array}{l}\text { 1. Limit the kinds of food } \\
\text { consumed }\end{array}$ & $1.87(1.14)$ & $1.78(1.15)$ & $1.78(0.81)$ & \\
\hline $\begin{array}{l}\text { 2. Trouble biting or } \\
\text { chewing }\end{array}$ & $1.96(1.2)$ & $1.91(1.27)$ & $1.78(1)$ & \\
\hline $\begin{array}{l}\text { 3. Able to swallow } \\
\text { comfortably }\end{array}$ & $2.2(1)$ & $1.81(1.47)$ & $1.41(1.15)$ & \\
\hline $\begin{array}{l}\text { 4. Unable to speak } \\
\text { clearly }\end{array}$ & $1.63(1)$ & $1.13(0.42)$ & $1.24(0.57)$ & \\
\hline $\begin{array}{l}\text { 5. Able to eat without } \\
\text { discomfort }\end{array}$ & $1.9(1.17)$ & $1.59(0.98)$ & $1.76(0.79)$ & \\
\hline $\begin{array}{l}\text { 6. Limit contact with } \\
\text { people }\end{array}$ & $1.45(0.9)$ & $1.34(0.75)$ & $1.3(0.73)$ & \\
\hline $\begin{array}{l}\text { 7. Pleased with appear- } \\
\text { ance of teeth }\end{array}$ & 2.85 (1.65) & $3.2(1.79)$ & $2.22(1.25)$ & \\
\hline 8. Use medication to & $1.83(1.08)$ & $1.94(1.13)$ & $1.87(0.88)$ & \\
\hline
\end{tabular}

relieve pain 